\title{
Pharyngeal Carcinoma by AJCC v8 Stage
}

National Cancer Institute

\section{Source}

National Cancer Institute. Pharyngeal Carcinoma by A/CC v8 Stage. NCI Thesaurus. Code C132814.

A term that refers to the staging of pharyngeal carcinoma according to the American Joint Committee on Cancer, 8th edition. 